\title{
Endoscopic Transforaminal Lumbar Foraminotomy: A Systematic Review and Meta-Analysis
}

\author{
Enrico Giordan (D) - Domenico Billeci (1) - Jacopo Del Verme · \\ Giustino Varrassi (i) · Flaminia Coluzzi (D)
}

Received: June 24, 2021 / Accepted: August 13, 2021 / Published online: September 6, 2021

(C) The Author(s) 2021

\begin{abstract}
Introduction: Spinal endoscopic techniques have recently been applied to complex degenerative conditions or failed back surgery syndrome. We performed a systematic review and meta-analysis to assess transforaminal endoscopic lumbar foraminotomy (TELF) outcomes and adverse event rates. We also analyzed the effectiveness of the technique for chronic pain after arthrodesis or previous spinal surgery.

Methods: Multiple databases were searched for studies published in the English language, involving patients $>18$ years old who underwent endoscopic foraminotomy. Outcomes included the rate of patients who showed "excellent" and "good" postoperative improvement, decreased leg pain, and improved Oswestry Disability Index (ODI) scores. Adverse
\end{abstract}

E. Giordan $(\bowtie) \cdot D$. Billeci $\cdot$ J. Del Verme Department of Neurosurgery, Aulss 2 Marca Trevigiana, Via Piazzale 1, 31100 Treviso, Veneto, Italy

e-mail: enrico.giordan@aulss2.veneto.it

G. Varrassi

Fondazione Paolo Procacci, Rome, Italy

F. Coluzzi

Department of Medical and Surgical Sciences and Biotechnologies, Sapienza University of Rome, Polo Pontino, Latina, Italy

F. Coluzzi

Sant'Andrea University Hospital, Rome, Italy events considered in the analysis included nerve root damage and intraoperative dural tear, the proportion of patients requiring revision surgery or recurrences, and infections.

Results: A total of 14 studies, encompassing 600 patients, were identified. Approximately $85 \%$ of patients improved significantly after TELF, without significant differences among different groups (85\% vs. $78 \%$, respectively). Mean leg pain decreased an average of 5.2 points, and ODI scores improved by $41.2 \%$. Patients with previous spine surgery or failed back surgery syndrome had higher postoperative leg dysesthesia rates after TELF (14\% vs. $1 \%$, respectively).

Conclusion: TELF is a useful and safe method to achieve decompression in foraminal stenosis. This technique is indicated in the elderly or patients with comorbidities. Preoperative planning is paramount in determining the foraminal size and endoscope trajectory. A diamond burr is recommended because it has an advantage over the regular endoscopic shaver in bleeding control and complication avoidance.

Keywords: Endoscopy; Lumbar; Foraminotomy; Spine; Foraminal; Stenosis 


\section{Key Summary Points}

We conducted a systematic review and meta-analysis of endoscopic foraminotomy (TELF) outcomes in the treatment of lumbar foraminal stenosis consequent to bony stenosis or lateral disc herniation.

We abstracted TELF outcomes and complications even in patients with failed back surgery syndrome (FBSS), degenerative spinal conditions (i.e., adjacent level degeneration), or who developed foraminal stenosis after fusion or fixation surgery.

Multiple databases were searched for studies published in English involving patients $>18$ years old who underwent endoscopic lumbar foraminotomy.

Our analysis estimated overall outcomes and adverse event rates and did not find significant differences in satisfactory outcomes or adverse events between the analyzed groups, except for higher rates of transient leg sensory disturbances in patients with previous surgery or with FBSS.

TELF results in terms of patients satisfaction (85\%), improvement of disability, and radiculopathy with pain are comparable to those of traditional miniinvasive or open procedures, with almost negligible adverse events rates.

Our study confirms the feasibility and safety of transforaminal endoscopic lumbar foraminotomy in a wide range of spine conditions, thus expanding the application of endoscopic techniques in spine surgery.

\section{INTRODUCTION}

The endoscopic approach to spine pathology has become an alternative to traditional open or mini-invasive techniques in selected cases. The outcomes are comparable to those observed with traditional techniques regarding postoperative pain, operative time, time to mobilization, and time to discharge. Also, endoscopic techniques have the advantage of almost negligible muscle damage, disc destruction, and blood loss [1-3].

Several authors reported transforaminal endoscopic lumbar foraminotomy (TELF) outcomes after treating lumbar foraminal stenosis $[4,5]$. The technique has expanded in the last two decades and has also recently been applied to complex degenerative conditions $[6,7]$, pain relief in the elderly $[8,9]$, or failed back surgery syndrome (FBSS) treatment [10]. The rationale behind this is that TELF allows the treatment of radicular pain consequent to primitive or secondary foraminal stenosis by acting on the causative agent of pain. In particular, in the transforaminal approach compared to the interlaminar, the surgeon can decompress the exiting nerve root, working on the foramen by a lateral approach, thus avoiding epidural scars.

The purpose of this study was to perform a systematic review and meta-analysis to assess overall rates of favorable outcomes and adverse events for endoscopic lumbar foraminotomy. An additional objective was to determine the results and complication rates concerning the technique for recurrent pain after arthrodesis or previous spinal surgery or at the adjacent level.

\section{METHODS}

A comprehensive search of several databases was performed. The search terms were "foraminotomy," "foraminectomy," "endoscopic," "transforaminal," "full-endoscopy," "endoscopy," and "lumbar," used alone and in combination. Databases included were PubMed, Epub Ahead of Print, Ovid MEDLINE In-Process \& Other Non-Indexed Citations, Ovid MEDLINE, Ovid EMBASE, Ovid Cochrane Central Register of Controlled Trials, Ovid Cochrane 
Database of Systematic Reviews, and Scopus. Controlled vocabulary supplemented with the keywords was used to search for endoscopic lumbar foraminotomy.

Inclusion criteria were the following:

1. studies published after 2000;

2. studies published in English;

3. studies with a mean or median followup > 6 months;

4. studies or series including:

a. patients with foraminal stenosis (i.e., studies concerning foraminotomy, foraminectomy);

b. patients with radiculopathy as the primary symptom;

c. patients with failed medical (resistant to oral nonsteroidal anti-inflammatory drugs [NSAIDs] or opioids) and physical therapy;

d. patients treated with transforaminal endoscopic techniques;

e. patients without previous lumbar spine surgery (either at same or at adjacent level);

f. patients who underwent spine surgery at the same or adjacent level;

g. patients with moderate to severe degenerative spinal disease (Meyerding grade I to III listhesis [11], coronal misalignment $\geq 10^{\circ}[12]$ );

h. patients with failed back surgery syndrome;

Studies with $<5$ patients, with patients with symptoms consequent to central canal stenosis, published in a language other than English, or with $<6$ months of follow-up were excluded. Two independent reviewers (E.G. and D.B.) selected the included studies.

\section{Data Abstraction}

For each study, we extracted the following information: patient age (years), sex, disease level, operative time (minutes), hospitalization time from intervention to discharge (days), follow-up (months), outcomes, intraoperative adverse events, long-term adverse events ( $>30$ days, both medical and surgical), proportion of recurrent disease at the same level and proportion of patients requiring revision surgery.
The outcomes were defined as satisfactory, based on MacNab scores [13], and values were collected at the last follow-up visit or at least $>12$ months after the intervention. We collected every MacNab outcome, and only "excellent" and "good" scores were considered satisfactory and then pooled together (percentage of patients with "excellent" and "good" scores over the total number of patients) in the meta-analysis models. MacNab's "fair" and "poor" scores were not included in the analysis because they were not considered of enough clinical importance to support the use of the endoscopic technique ("fair" values were considered unsatisfactory).

Pain assessment of the symptomatic leg, by using an 11-point visual analog scale (VAS), and functionality, by using the Oswestry Disability Index [14] values, were collected preoperatively and at the last follow-up.

Recurrence of the symptoms at the treated level was considered a recurrent disease, regardless of whether the patient required reoperation.

Revision surgeries were considered every other intervention at the previously treated or adjacent level (i.e., additional arthrodesis to overcome a developing spinal instability) for symptoms control.

Intraoperative adverse events were considered: nerve root damage (temporary vs. permanent motor weakness or dysesthesia) and intraoperative dural tears. Epidural hematoma and infections were deemed to be major surgical adverse events.

When possible, we separately extracted and analyzed the subpopulations of patients with first-time foraminal stenosis (i.e., primary foraminal stenosis) or patients who have already had an intervention at the same or adjacent level, or with a diagnosed FBSS, or diagnosed with degenerative spinal disease.

This article is based on previously conducted studies and does not contain any new studies with human participants or animals performed by any of the authors. 


\section{Study Evaluation}

From each study, we evaluated the study design, study population, and follow-up duration. We also evaluated the risk of bias. To assess the risk of bias, we modified the New Castle-Ottawa Quality Assessment Scale [15]. The risk of bias was assessed based on the following questions: Did the study include all patients or consecutive patients with adequate follow-up ( $\geq 24$ months)? Was the study population big enough to make solid prognostic considerations ( $\geq 50$ patients)? Was the study design fair (prospective vs. retrospective)? Were spine stability changes assessed after the foraminotomy?

Studies judged to be at low risk of bias were defined as those with a predefined study protocol (randomized trial or prospective), $\geq 50$ patients, spine stability parameters assessed after the procedure, and adequate imaging follow-up ( $\geq 24$ months). The studies were divided into "high" and "low" risk of bias, and a separate analysis was done comparing the two tiers to see whether there was any statistically significant difference.

\section{Statistical Analysis}

For each cohort, the proportion of patients considered improved, and the proportion of patients with adverse events were estimated. Estimates from each cohort were pooled in a random-effects model meta-analysis as described by DerSimonian and Laird. Anticipating heterogeneity between studies, we chose this model a priori because it incorporates withinstudy variance and between-study variance. Also, because the rate of outcomes was close to 0 or 1 in some studies, the Freeman-Tukey double arcsine transformation was utilized. All statistical analyses were performed using Stata version 13.0 (StataCorp).

\section{RESULTS}

\section{Literature Search and Study Characteristics}

The initial literature search yielded 189 articles. Upon review of abstracts and titles, 138 articles were excluded. On secondary review, 37 articles were excluded because they did not match the eligibility criteria for this meta-analysis, mainly regarding the length of follow-up, endoscopic foraminotomy, or outcomes definition.

In total, 14 studies describing the outcomes and adverse events of transforaminal endoscopic foraminotomy were included. These studies included 600 patients. Seven of these 14 studies reported the results in series with primary lumbar foraminal stenosis (452 patients). Four studies concerned foraminal stenosis developed after previous spinal surgery (i.e., developing at the same level or part of adjacent level disease) or as part of failed back surgery syndrome (96 patients). Three studies described the outcomes in cases with a degenerative spinal disease (52 patients). Nine studies were retrospective, and five were prospective. Of the 14 studies included, five had a high risk of bias, and nine had a low risk of bias. A study-selection flow diagram compiled following the PRISMA guidelines is provided in Fig. 1 [16]. A summary of the included studies is provided in Table 1. Methodological quality indicators are summarized in Table 2. Overall, these noncomparative series appeared to have adequate quality.

\section{Outcome Analysis}

Overall, the mean age was 60.9 years (range 42.4-79.9 years), with mean operative times ranging from 48 to $73 \mathrm{~min}$. The majority of patients were female $(67.4 \%)$, and the most treated level was L4-L5 (53.1\%), followed by L5-S1 (32\%), L3-L4 (12.7\%), L2-L3 (1.6\%), and L1-L2 $(0.6 \%)$. All patients underwent the procedure under local anesthesia, with or without intravenous sedation. Hospitalization times ranged from 12 to $34 \mathrm{~h}$, and mean follow-up was 21.3 months (range 6 to 46 months). 
189 records identified trough database searching or additional sources

$\checkmark \begin{aligned} & \mathbf{1 3 8} \text { excluded after limit to lumbar } \\ & \text { compartment, years 2000, English } \\ & \text { language and duplicates }\end{aligned}$

$\mathbf{5 1}$ articles identified and screened
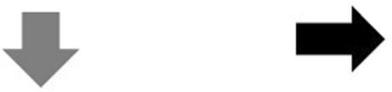

$\mathbf{1 4}$ studies provided adequate data for analysis
37 excluded for being review articles, case reports or for not matching the requirements for metaanalysis eligibility (i.e. missing relevant information)

Fig. 1 Flow diagram summarizing the process of study selection

Overall, most patients experienced satisfactory improvement $\quad(84.6 \% \quad[95 \% \quad \mathrm{CI}$ 78.2-90.2\%]) after endoscopic foraminotomy (Fig. 2). Leg pain decreased by an average of 5.2 points $(S D \pm 0.9)$, from a starting value of 7.4 $(\mathrm{SD} \pm 1.1)$. Basal average ODI scores were $58.4 \%$ (SD $\pm 13.7 \%$ ), and improved by an average of $41.2 \%(\mathrm{SD} \pm 14.8 \%)$.

When comparing the proportion of patients who had satisfactory outcomes between patients with primary foraminal stenosis and foraminal stenosis after previous spine surgery or failed back surgery syndrome $(85.3 \%$ [95\% CI 76.8-92.2\%] vs. $78.4 \%$ [95\% CI $65.0-89.7 \%$ ], respectively) we found a mild but not statistically significant difference. Again, no differences were found when comparing the satisfactory outcomes of primary lumbar foraminal stenosis with series of patients with advanced degenerative spinal diseases $(85.3 \%$ $\left[\begin{array}{lll}95 \% & \text { CI } & 76.7-92.2 \%\end{array}\right]$ vs. $90.0 \% \quad[95 \%$ CI 70.3-100.0\%], respectively).

\section{Adverse Events Analysis}

Overall, intraoperative dural tear rate was $0.9 \%$ (95\% CI $0.0-1.0 \%)$, while overall postoperative transient leg dysesthesia rate was $2.4 \%$ (95\% CI $0.1-6.6 \%)$. All the intraoperative dural tears were repaired intraoperatively, and none required additional intervention. All of the postoperative leg root disturbances spontaneously solved or after short-course oral corticosteroid administration. Overall, same-level recurrent stenosis rate was $1.4 \% \quad(95 \%$ CI $0.0-4.3 \%)$ Fig. 3A, while revision surgery rate was $1.2 \%$ (95\% CI $0.0-3.7 \%)$ Fig. 3B

Comparing patients who underwent primary foraminotomy and patients with foraminotomy after previous spine surgery or FBSS, no significant differences were found in intraoperative dural tear, recurrence, or revision rates.

A significant increase in temporary leg dysesthesia after foraminotomy was reported in patients with previous spine surgery or failed back surgery syndrome $(14.0 \% \quad[95 \%$ CI $7.7-21.5 \%]$ vs. $1.3 \% \quad[95 \%$ CI $0.0-4.2 \%$, respectively).

After comparing primary foraminotomy adverse events rates to foraminotomy in patients with a degenerative spinal disease, a slightly higher revision surgery rate was detected in the latter group of patients $(4.4 \%$ [95\% CI 


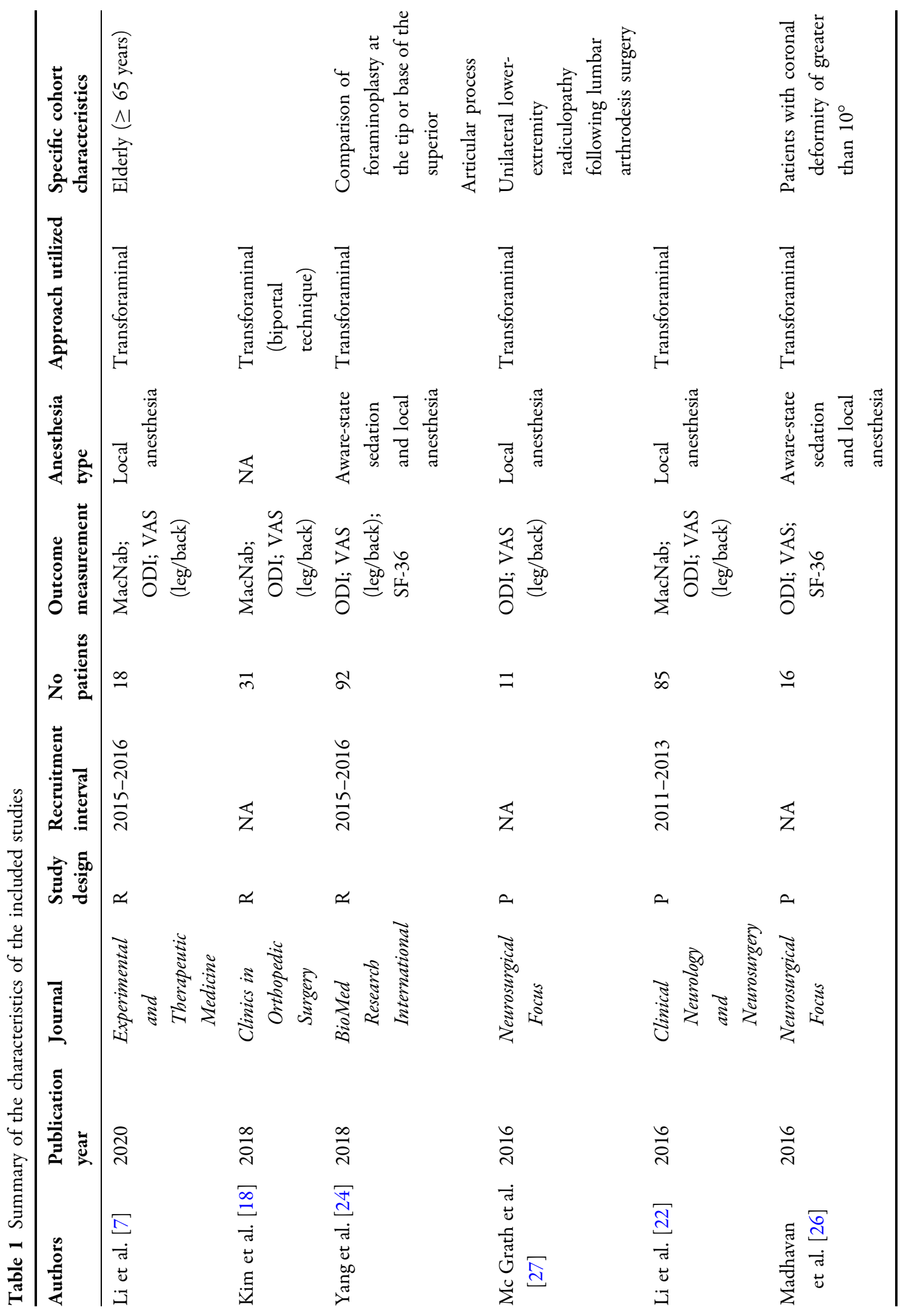




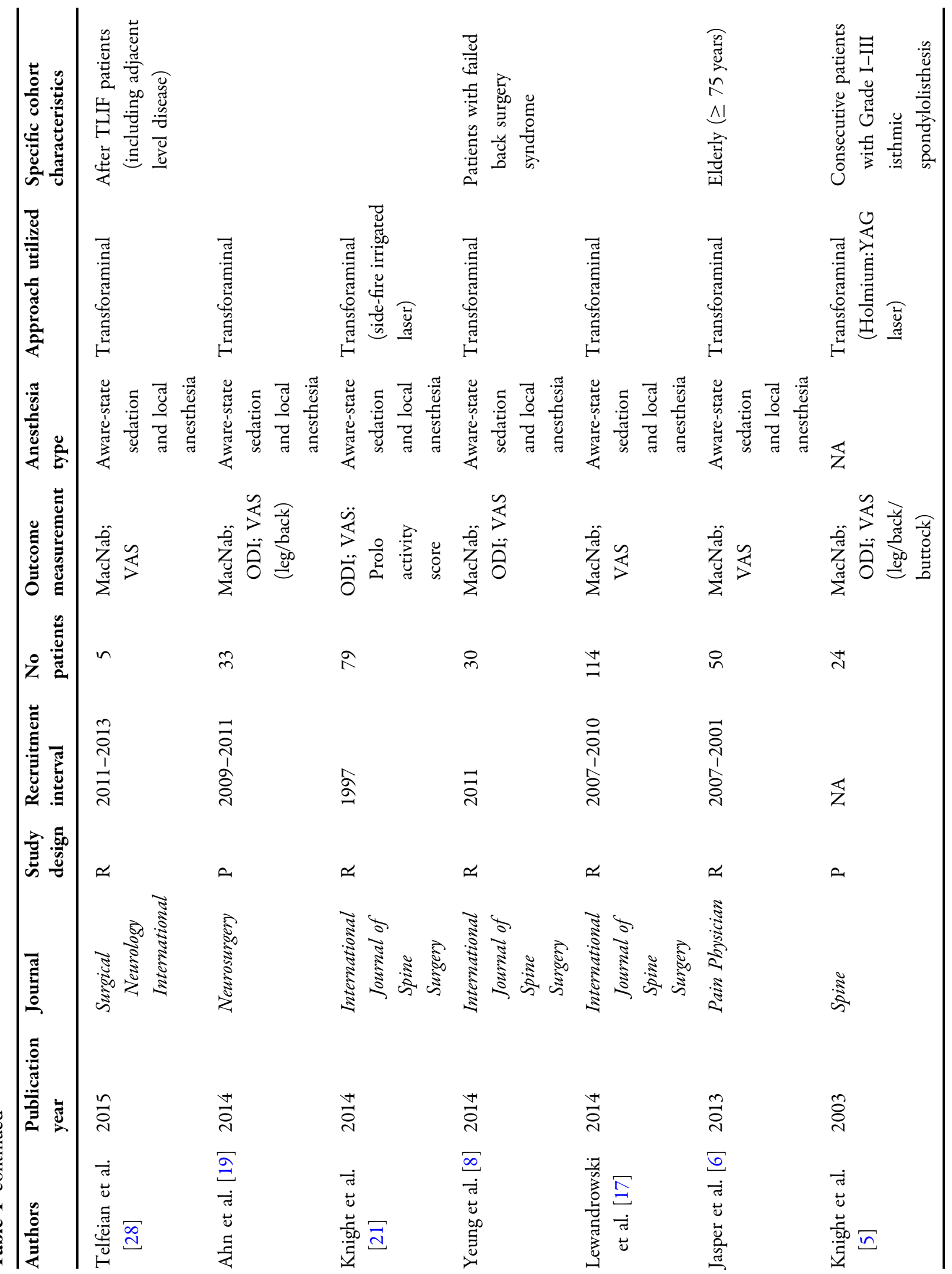




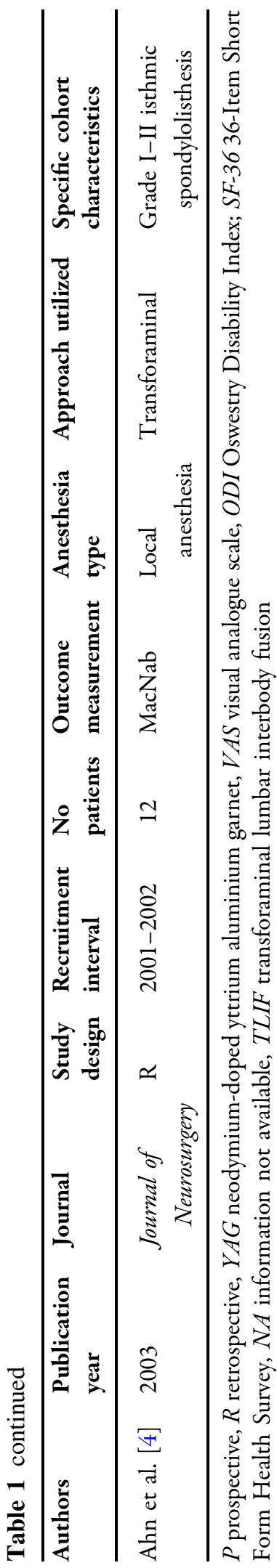

$0.0-13.0 \%$ ] vs. $1.4 \%$ [95\% CI $0.0-4.9 \%$, respectively), followed by a slightly higher recurrence rate $(2.6 \%$ [95\% CI $0.0-11.4 \%]$ vs. $1.4 \%$ [95\% CI 0.0-4-7\%], respectively). No differences were found in terms of intraoperative dural tears. There were no major surgical and adverse medical events in the examined pool of patients.

\section{DISCUSSION}

Our review estimated overall outcomes and adverse event rates for the whole pool of patients and between patients who had already experienced spinal surgery, failed back surgery syndrome, or moderate to severe spine degenerative disease. We did not find significant differences in satisfactory outcomes or adverse events between the analyzed groups, except for higher rates of transient leg sensory disturbances in patients with previous surgery or diagnosed with FBSS. A long history of myelin sheath disease can explain those findings. Indeed, when the dural sheath is damaged or, in any case, more vulnerable, further stimulation can cause damage to the nerve root, with consequences for normal conduction of nervous stimulus.

Our analysis confirms the feasibility and safety of transforaminal endoscopic lumbar foraminotomy in a wide range of spine conditions. Our results in terms of patient satisfaction $(85 \%)$, improvement of disability (>40\% of ODI scores), and radiculopathy with pain ( $>4$ points in leg VAS) are comparable to those of traditional mini-invasive or open procedures $[17,18]$. However, one of the main limitations of the examined papers is the lack of information about the quality of pain with a neuropathic component. Outcomes have been merely evaluated by using a quantitative score (VAS), while other specific tools, such as the Doleur Neuropathique questionnaire (DN4) could be helpful in classifying patients with transient leg sensory disturbances [17]. While most of the studies used ODI as a valuable index of functionality, only two trials reported the 36-Item Short Form Health Survey (SF-36) scores, a multidimensional scale commonly used for 
Table 2 Methodological quality evaluation

\begin{tabular}{|c|c|c|c|c|c|c|c|}
\hline \multirow{2}{*}{\multicolumn{2}{|c|}{$\frac{\text { Included studies }}{\text { Authors, years }}$}} & \multirow{3}{*}{$\begin{array}{l}\text { Representativeness } \\
\text { of exposed cohort }\end{array}$} & \multirow{2}{*}{$\begin{array}{l}\text { Selection of non- } \\
\text { exposed cohort }\end{array}$} & \multirow{2}{*}{$\begin{array}{l}\text { Ascertainment } \\
\text { of exposure }\end{array}$} & \multirow{2}{*}{$\begin{array}{l}\text { Study } \\
\text { design }\end{array}$} & \multicolumn{2}{|l|}{ Outcome } \\
\hline & & & & & & Assessment & Length of \\
\hline Li et al. [7] & 2020 & & & & & 000 & $\bullet$ \\
\hline Kim et al. [18] & 2018 & $\bullet$ & & & & 000 & \\
\hline Yang et al. [24] & 2018 & 0 & 0 & & & 000 & 0 \\
\hline $\begin{array}{l}\text { Mc Grath et al. } \\
\text { [27] }\end{array}$ & 2016 & $\bullet$ & & $\bullet$ & $\bullet$ & $\bullet$ & \\
\hline $\mathrm{Li}$ et al. [22] & 2016 & $\bullet$ & $\bullet$ & $\bullet$ & 0 & 000 & 0 \\
\hline $\begin{array}{l}\text { Madhavan } \\
\text { et al. [26] }\end{array}$ & 2016 & 0 & & 0 & 0 & 000 & \\
\hline $\begin{array}{l}\text { Telfeian et al. } \\
\text { [28] }\end{array}$ & 2015 & $\bullet$ & & $\bullet$ & & $\bullet$ & \\
\hline Ahn et al. [19] & 2014 & 0 & & 0 & 0 & 000 & 0 \\
\hline $\begin{array}{l}\text { Knight et al. } \\
\text { [21] }\end{array}$ & 2014 & 0 & 0 & & & 000 & $\bullet$ \\
\hline Yeung et al. [8] & 2014 & ○ & & & & $\bullet \bullet$ & ○ \\
\hline $\begin{array}{c}\text { Lewandrowski } \\
\text { et al. }[17]\end{array}$ & 2014 & ○ & ○ & & & $\bullet$ & 0 \\
\hline Jasper et al. [6] & 2013 & $\bullet$ & $\bullet$ & & & $\bullet$ & \\
\hline $\begin{array}{l}\text { Knight et al. } \\
{[5]}\end{array}$ & 2003 & ○ & & - & ○ & $\bullet 00$ & • \\
\hline Ahn et al. [4] & 2003 & $\bullet$ & & $\bullet$ & & $\bullet$ & \\
\hline
\end{tabular}

evaluating patients with chronic pain, in terms of physical and mental health-related quality of life [18]. Finally, selected papers did not report information about analgesic treatments before and after procedures.

Lumbar foraminal stenosis is a relatively common disease that accounts for approximately $8-11 \%$ of degenerative lumbar spines [5]. Because of nerve root compression, sympathetic foraminal stenosis is classically associated with a posterior intervertebral disc height of $2 \mathrm{~mm}$ or less and a neuroforaminal height of less than $15 \mathrm{~mm}$ [19]. Foraminal decompression may be achieved by undercutting the hypertrophied superior facet, removing the foraminal disc herniation and ligament, and releasing fibrotic adhesions[6].

Indeed, lumbar foraminotomy differs from other spinal decompressive procedures because it targets the foraminal zone's irritants $[3,3]$.

TELF allows the surgeon to explore the foramen while ablating osteophytes, protruded disc, and epidural fibrosis [6, 21]. For decompression laser, reamers and drills have been proposed over the years. However, laser is useful only for neural entrapment caused by soft tissue or fragile osteophytes. Simultaneously, bone reamers can rapidly cut the hypertrophied bone, but the foraminal area's advancement cannot be seen [21]. Some authors also believe that TELF for stenosis in the neuroforamen's 


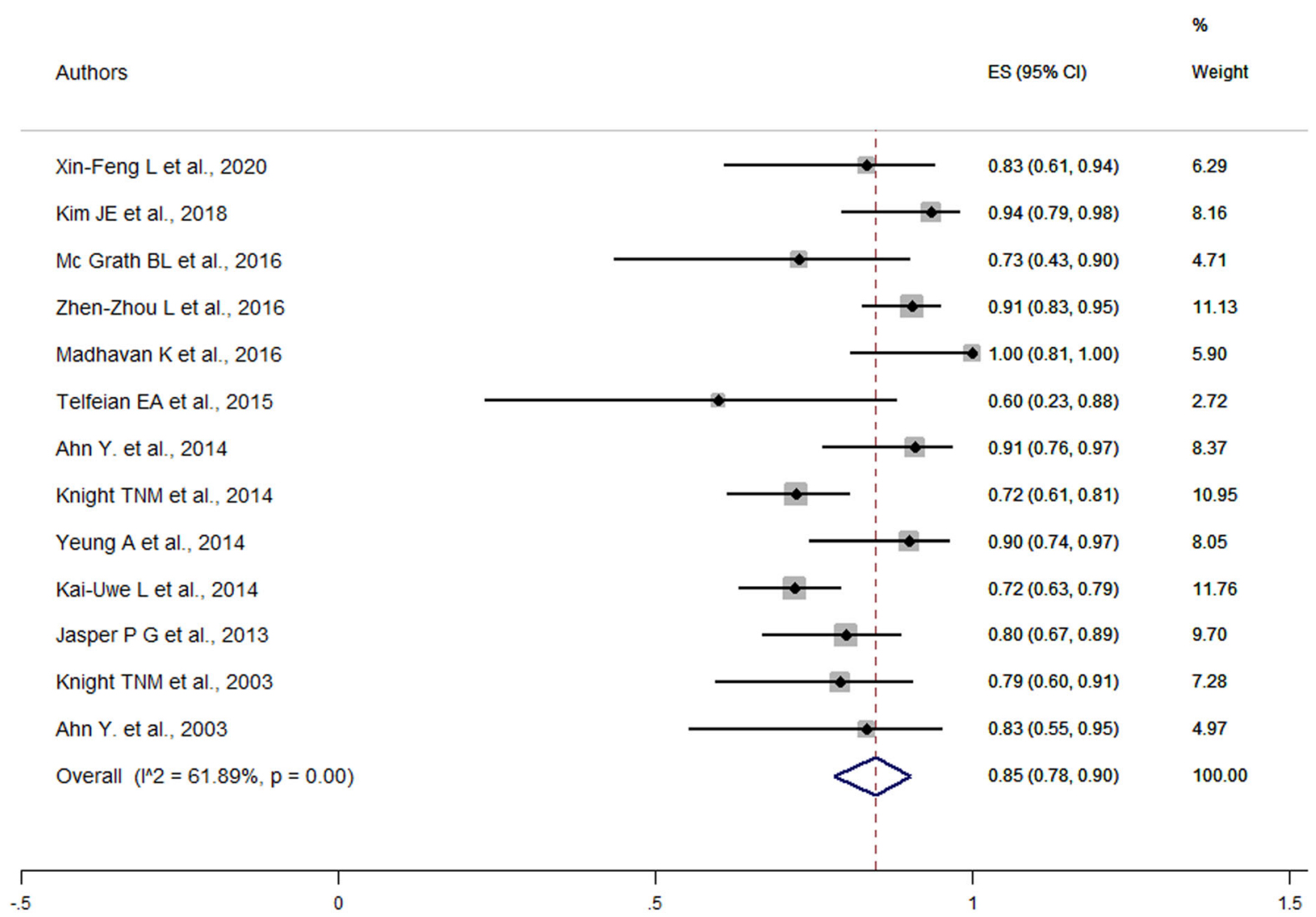

Fig. 2 Forest plot for overall improved outcomes

entry zone (i.e., the most paramedian zone) has worse outcomes than in the treatment of stenosis in the middle and exit zones [19].

Studies on conventional open, microscopic, or mini-invasive foraminotomy demonstrated success rates of 76.9-83\% [4], which aligns with our results (78-90\%). Several complications such as nerve root weakness, hematoma, and seroma were reported with the same rates as ours in conventional open or mini-invasive foraminal decompression series [22, 23], but with relatively longer (127-156 min) operative times. Ahn et al. and Knight et al. reported $6.1-19.1 \%$ of postoperative dysesthesia after endoscopic foraminotomy with a high-speed endoscopic drill. These short-lived symptoms are most likely due to irritation of the exiting nerve or ganglion $[4,23]$.

Our study also highlights the procedure's feasibility at all lumbar levels, with particular attention in the case of a high level of the iliac crest, thick transverse process, and marginal osteophytes, which may complicate the surgery at all L5-S1 level [23, 24].

TELF itself does not interfere with the traditional deformity exposure and minimizes dural scars and complications related to revision surgeries [23]. It effectively decompresses the foramen without further destabilizing the articular process $[7,8]$. Also, it avoids scar tissue caused by previous traditional procedures performed via an interlaminar corridor [7].

Osman et al. explored the foraminal area's anatomy and spine flexibility changes between posterior and transforaminal decompression [25]. He found that a $45.5 \%$ increase in the intervertebral foraminal area was possible after endoscopic foraminotomy without flexibility change [26]. In this meta-analysis, no significant differences were found in the slippage percentage between the preoperative stage and the end of the follow-up. There was no documented radiological progression of the instability in the included studies [20]. 
A

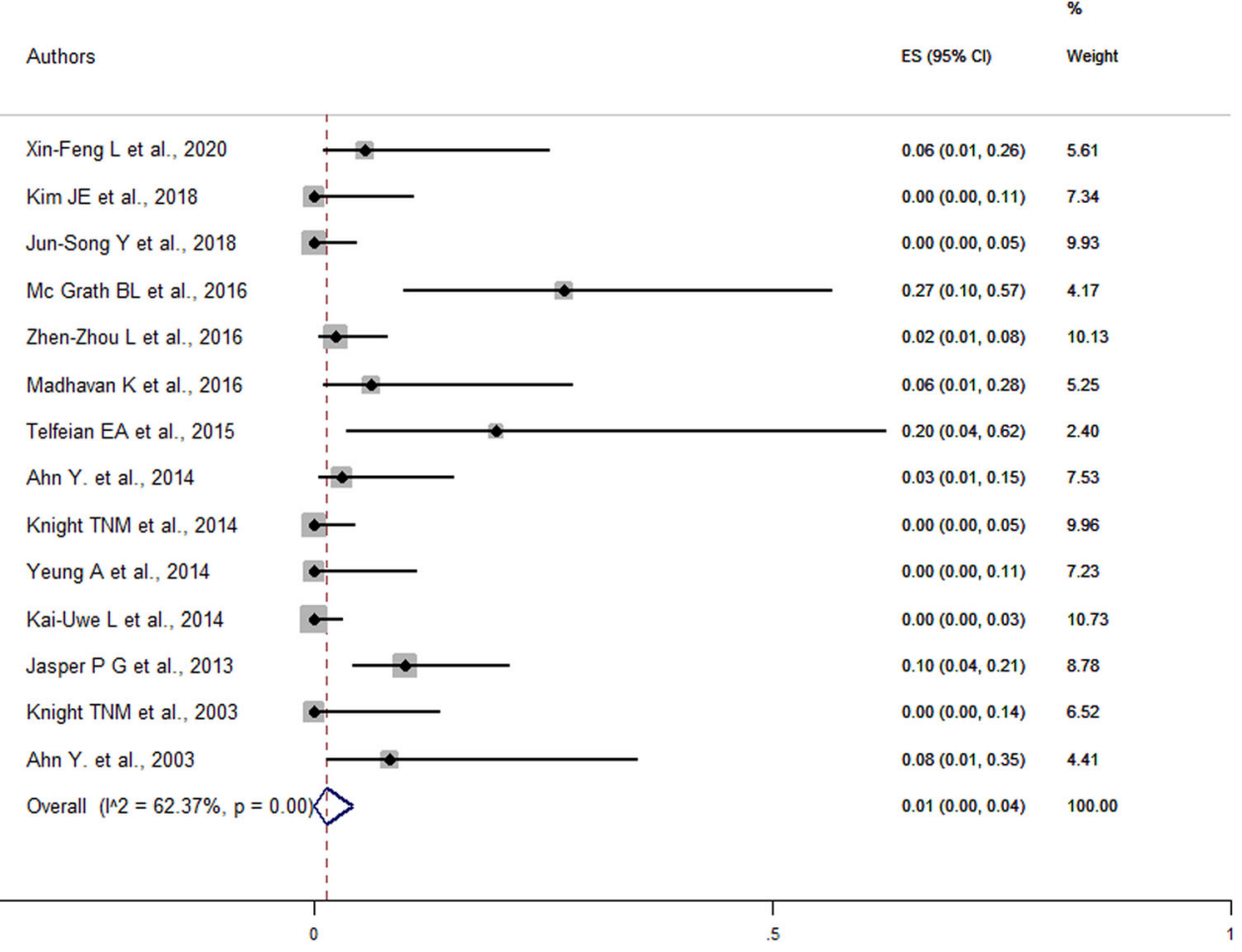

B $\%$

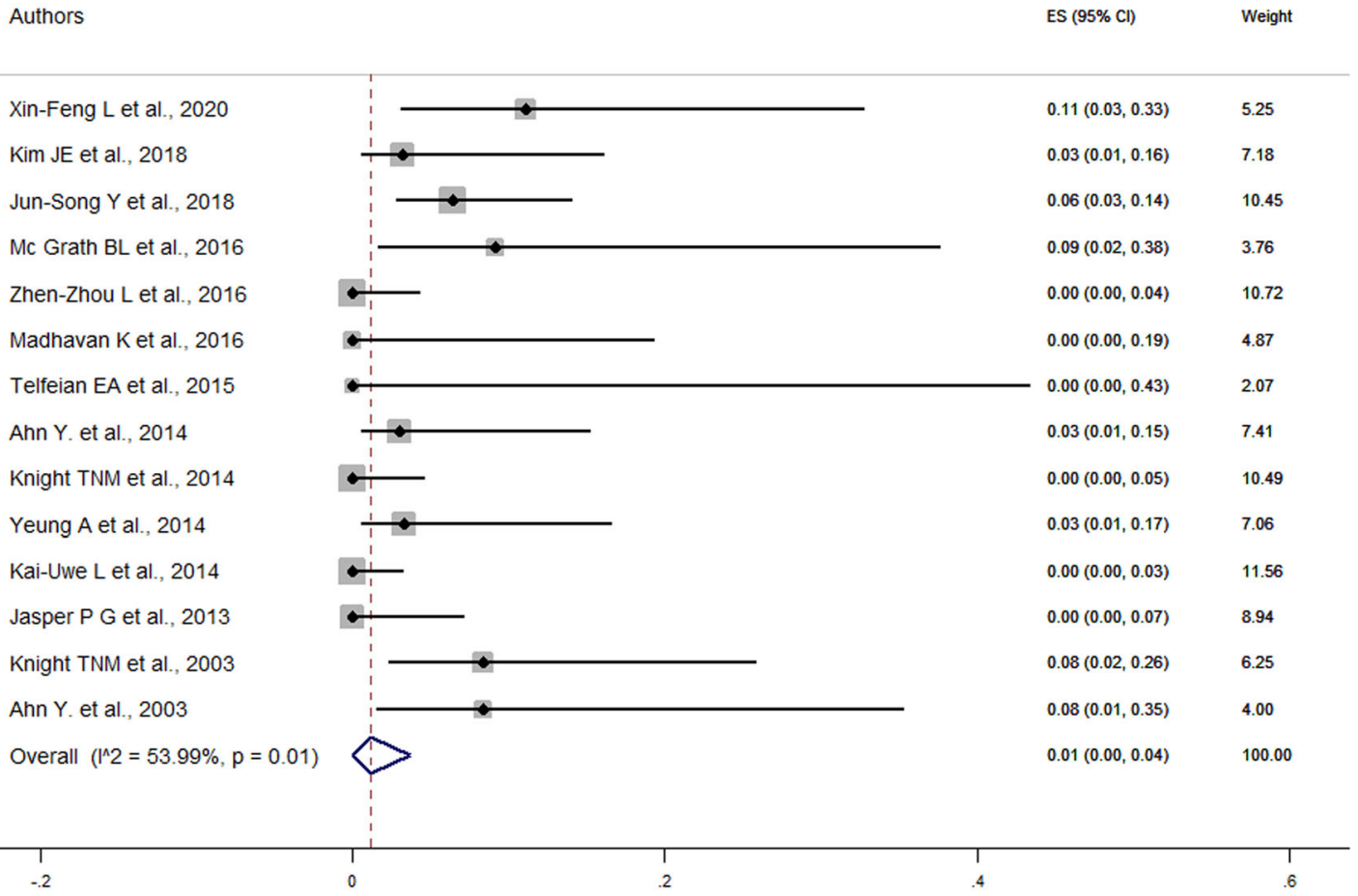

Fig. 3 a Forest plot for the rate of intraoperative adverse events. b Forest plot for the rate of revision surgery 
Eventually, one of the most crucial aspects of a successful procedure is the accurate diagnosis of the condition in terms of location, nature, and extent. Several authors showed how in severe central canal stenosis, TELF has little effect because of the limited decompression [6]. Therefore, careful patient selection and imaging preparation maximize the outcomes. Foramen size and additional disc compression are factors to bear in mind in the operative planning [27].

In line with our results, some authors showed that the rate of post-surgical revision was low, with $5.6 \%$ of patients requiring a subsequent micro-decompression surgery at a mean follow-up of 27.7 months [9]. Also, as evidenced in our pool of studies, intraoperative dural tear never requires additional care despite intraoperative fibrin glue or fibrin matrix apposition; this is because the skin incision is such a small and the trajectory so lateral and long that makes the risk of CFS fistula almost negligible.

TELF was also proposed as a "rescue" procedure in the setting of lumbar disc re-herniation or foraminal stenosis after instrumented lumbar fusion. Indeed, it was estimated that the number of patients requiring revision surgery with the extension of fusion constructs is nearly $10 \%$ at 2 years of follow-up, and $29 \%$ of all patients will need to undergo further fusion [28]. Often patients with deformity complain of radicular pain due to foraminal stenosis. These patients have tolerable levels of back pain from deformity but may have severe focal radicular pain. Revision surgery involves revision of instrumentation or extension of the fusion construct to additional levels and might become a morbidity-producing surgery. In a recent study, $\mathrm{O}^{\prime}$ Neill et al. revealed significant surgical complications in $27 \%$ of patients, and $25 \%$ had reoperation. So unless there are strong indications to undertake deformity correction surgery, smaller procedures aiming to provide symptomatic relief from radicular pain may be worth considering [5, 29].

Eventually, TELF may be an alternative strategy for patients who suffer from radiculopathy following arthrodesis surgery. Our results seem to indicate that highly targeted endoscopic decompression of nerve roots within a successful arthrodesis construct is feasible and may result in symptomatic relief [30]. TELF avoids a repeat posterior approach, is truly minimally invasive and does not require general anesthesia $[24,30]$. For these reasons, TELF is particularly suitable for frail patients, such as older adults. Indeed, longer life expectancy correlates with an increased incidence of additional spine surgery due to adjacent-level breakdown, iatrogenic instability, or other postoperative complications. Moreover, all the authors in our studies utilized local anesthesia with the adjunct of intravenous sedation, avoiding time-consuming and risky general anesthesia.

As aforementioned, every "redo" spine surgery in itself is quite complicated, and more so when it is performed in the elderly population [28]. Elderly patients suffering from monoradiculopathy may not tolerate the general anesthesia, as required for a complete foraminal decompression and fusion surgery [9], thus making TELF alone a feasible and safe procedure for symptoms relief [8].

\section{Limitations}

The main limitation is the lack of individual patient data, making predictive analysis subject to confounding bias. Also, six studies were estimated to have an elevated risk of bias. Furthermore, the chance of an inter-and intra-observer variability is not negligible, and not all of the studies reported every outcome evaluated in this review. This may have impacted the results, but every attempt was made to account for heterogeneity.

Moreover, studies included in this metaanalysis were selected following a strict a priori search protocol, including multiple databases. The study selection was also rigorous and based on the criteria established by the most recent guidelines. Eventually, we are aware that our analysis lacks randomized studies on the topic and that the level of evidence is relatively low (mostly level III), but that is the best is currently available from the literature. We believe that reporting TELF results will improve decisionmaking in patients with foraminal stenosis and helping surgeons to expand the thinking 
process outside the box of standard procedures. This is particularly true in salvage surgeries in already instrumented or fused patients, where TELF could be of great use.

\section{CONCLUSIONS}

TELF is a useful and safe method to achieve decompression in foraminal stenosis. This technique is mainly indicated in the elderly or patients not eligible for major surgery. Accurate radiological preoperative planning is paramount for determining the foraminal size and endoscope trajectory. Drilling the foraminal zone is recommended for the regular endoscopic shaver because of improved bleeding control and complication avoidance.

\section{ACKNOWLEDGEMENTS}

Funding. No funding or sponsorship was received for this study or publication of this article.

Authorship. All named authors meet the International Committee of Medical Journal Editors (ICMJE) criteria for authorship for this article, take responsibility for the integrity of the work as a whole, and have given their approval for this version to be published.

Authors' Contributions. (I) Conception and design: Giordan E, Del Verme J, Billeci D; (II) Administrative support: Giordan E; (III) Provision of study materials or patients: Giordan E, Canova G; (IV) Collection and assembly of data: Giordan E, Del Verme J, Billeci D; (V) Data analysis and interpretation: Giordan E, Del Verme J, Billeci D; Varrassi G; (VI) Manuscript writing: Giordan E, Billeci D, Coluzzi F; (VII) Final approval of manuscript: All authors.

Disclosures. Dr. Enrico Giordan, Domenico Billeci, Jacopo Del Verme, Giustino Varrassi, Flaminia Coluzzi have nothing to disclose and certify that they have no affiliations with or involvement in any organization or entity with any financial interest (such as honoraria; educational grants; participation in speakers' bureaus; membership, employment, consultancies, stock ownership, or other equity interest; and expert testimony or patent-licensing arrangements), or non-financial interest (such as personal or professional relationships, affiliations, knowledge or beliefs) in the subject matter or materials discussed in this manuscript.

Compliance with Ethics Guidelines. This article is based on previously conducted studies and does not contain any new studies with human participants or animals performed by any authors.

Data Availability. The datasets generated during and/or analyzed during the current study are available from the corresponding author on reasonable request.

Open Access. This article is licensed under a Creative Commons Attribution-NonCommercial 4.0 International License, which permits any non-commercial use, sharing, adaptation, distribution and reproduction in any medium or format, as long as you give appropriate credit to the original author(s) and the source, provide a link to the Creative Commons licence, and indicate if changes were made. The images or other third party material in this article are included in the article's Creative Commons licence, unless indicated otherwise in a credit line to the material. If material is not included in the article's Creative Commons licence and your intended use is not permitted by statutory regulation or exceeds the permitted use, you will need to obtain permission directly from the copyright holder. To view a copy of this licence, visit http://creativecommons.org/licenses/by$\mathrm{nc} / 4.0 /$.

\section{REFERENCES}

1. Tacconi L, Signorelli F, Giordan E. Is full endoscopic lumbar discectomy less invasive than conventional surgery? A randomized MRI study. World 
Neurosurg [Internet]. 2020;138:e867-75. https:// doi.org/10.1016/j.wneu.2020.03.123.

2. Meloncelli S, Germani G, Urti I, Divizia M, Rosciano M, Puntillo F, et al. Endoscopic radiofrequency facet joint treatment in patients with low back pain: technique and long-term results. A prospective cohort study. Ther Adv Musculoskelet Dis. 2020;12:1759720X20958979.

3. Divizia M, Germani G, Urti I, Imani F, Varrassi G, Meloncelli S. Endoscopic neuromodulation of suprascapular nerve in chronic shoulder pain: A case report. Anesth Pain Med. 2020;10(2):e103624. https://doi.org/10.5812/aapm.103624

4. Sairyo K, Chikawa T, Nagamachi A. State-of-the-art transforaminal percutaneous endoscopic lumbar surgery under local anesthesia: Discectomy, foraminoplasty, and ventral facetectomy. J Orthop Sci [Internet]. 2018;23:229-36. https://doi.org/10. 1016/j.jos.2017.10.015.

5. Evins AI, Banu MA, Njoku I, Elowitz EH, Härtl R, Bernado A, et al. Endoscopic lumbar foraminotomy. J Clin Neurosci [Internet]. 2015;22:730-4. https://doi.org/10.1016/j.jocn.2014.10.025.

6. Ahn Y, Lee SH, Park WM, Lee HY. Posterolateral percutaneous endoscopic lumbar foraminotomy for L5-S1 foraminal or lateral exit zone stenosis. Technical note. J Neurosurg. 2003;99:320-3.

7. Knight M, Goswami A. Management of isthmic spondylolisthesis with posterolateral endoscopic foraminal decompression. Spine (Phila Pa 1976). 2003;28:573-81.

8. Jasper GP, Francisco GM, Telfeian AE. A retrospective evaluation of the clinical success of transforaminal endoscopic discectomy with foraminotomy in geriatric patients. Pain Physician. 2013;16:225-9.

9. Li XF, Jin LY, Lv ZD, Su XJ, Wang K, Shen HX, Song $X X$. Efficacy of percutaneous transforaminal endoscopic decompression treatment for degenerative lumbar spondylolisthesis with spinal stenosis in elderly patients. Exp Ther Med. 2020;19(2): 1417-24. https://doi.org/10.3892/etm.2019.8337.

10. Yeung A, Gore S. Endoscopic foraminal decompression for failed back surgery syndrome under local anesthesia. Int J Spine Surg [Internet]. 2014. https://doi.org/10.14444/1022.

11. Niggemann P, Kuchta J, Grosskurth D, Beyer HK, Hoeffer J, Delank KS. Spondylolysis and isthmic spondylolisthesis: impact of vertebral hypoplasia on the use of the Meyerding classification. Br J Radiol. 2012;85:358-62.
12. Aebi M. The adult scoliosis. Eur Spine J Off Publ Eur Spine Soc Eur Spinal Deform Soc Eur Sect Cerv Spine Res Soc Germ. 2005;14:925-48.

13. Macnab I. Negative disc exploration. An analysis of the causes of nerve-root involvement in sixty-eight patients. J Bone Jt Surg Am United States. 1971;53: 891-903.

14. Fairbank JC, Pynsent PB. The oswestry disability index. Spine (Phila Pa 1976). 2000;25(22):2940-52; discussion 2952. https://doi.org/10.1097/00007 632-200011150-00017.

15. Lo CKL, Mertz D, Loeb M. Newcastle-Ottawa Scale: comparing reviewers' to authors' assessments. BMC Med Res Methodol [Internet]. 2014;14:1-5.

16. Liberati A, Altman DG, Tetzlaff J, Mulrow C, Gotzsche PC, Ioannidis JPA, et al. The PRISMA statement for reporting systematic reviews and meta-analyses of studies that evaluate healthcare interventions: explanation and elaboration. BMJ England. 2009;339:2700.

17. Morgenstern R, Morgenstern C, Yeung AT. The learning curve in foraminal endoscopic discectomy: experience needed to achieve a $90 \%$ success rate. SAS J [Internet]. 2007;1:100-7. https://doi.org/10. 1016/S1935-9810(07)70054-3.

18. Knight MTN, Ellison DR, Goswami A, Hillier VF. Review of safety in endoscopic laser foraminoplasty for the management of back pain. J Clin Laser Med Surg. 2001;19:147-57.

19. Lewandrowski KU. "Outside-in" technique, clinical results, and indications with transforaminal lumbar endoscopic surgery: a retrospective study on 220 patients on applied radiographic classification of foraminal spinal stenosis. Int J Spine Surg [Internet]. 2014;8:26. https://doi.org/10.14444/1026.

20. Kim JE, Choi DJ, Park EJ. Clinical and radiological outcomes of foraminal decompression using unilateral biportal endoscopic spine surgery for lumbar foraminal stenosis. CiOS Clin Orthop Surg. 2018;10:439-47.

21. Ahn Y, Oh HK, Kim H, Lee SH, Lee HN. Percutaneous endoscopic lumbar foraminotomy: an advanced surgical technique and clinical outcomes. Neurosurgery. 2014;75:124-32.

22. Ross DA. Complications of minimally invasive, tubular access surgery for cervical, thoracic, and lumbar surgery. Minim Invasive Surg. 2014;2014: 451637. https://doi.org/10.1155/2014/451637.

23. Barber SM, Nakhla J, Konakondla S, Fridley JS, Oyelese AA, Gokaslan ZL, Telfeian AE. Outcomes of endoscopic discectomy compared with open 
microdiscectomy and tubular microdiscectomy for lumbar disc herniations: A meta-analysis. J Neurosurg Spine. 2019;6:1-14. https://doi.org/10.3171/ 2019.6.SPINE19532.

24. Knight MTN, Jago I, Norris C, Midwinter L, Boynes $\mathrm{C}$, Acu L. Transforaminal endoscopic lumbar decompression \& foraminoplasty: a 10 year prospective survivability outcome study of the treatment of foraminal stenosis and failed back surgery. Int J Spine Surg [Internet]. 2014;8:21. https://doi.org/10.14444/1021.

25. Osman SG, Nibu K, Panjabi MM, Marsolais EB, Chaudhary R. Transforaminal and posterior decompressions of the lumbar spine. A comparative study of stability and intervertebral foramen area. Spine (Phila Pa 1976). 1997;22(15):1690-1695. https://doi.org/10.1097/00007632-19970801000002.

26. Yang JS, Chu L, Chen CM, Wang XF, Xie PG, Deng R, Yu KX, Shi L, Zhang ZX, Rong LM, Hao DJ, Deng ZL. Foraminoplasty at the tip or base of the superior articular process for lateral recess stenosis in percutaneous endoscopic lumbar discectomy: A multicenter, retrospective, controlled study with 2-year follow-up. Biomed Res Int. 2018;2018: 7692794. https://doi.org/10.1155/2018/7692794.

27. Leven D, Passias PG, Errico TJ, Lafage V, Bianco K, Lee A, et al. Risk factors for reoperation in patients treated surgically for intervertebral disc herniation: a subanalysis of eight-year SPORT data. J Bone Jt Surg Am United States. 2015;97:1316-25.

28. Madhavan K, Chieng LO, McGrath L, Hofstetter CP, Wang MY. Early experience with endoscopic foraminotomy in patients with moderate degenerative deformity. Neurosurg Focus. 2016;40:1-5.

29. McGrath LB, Madhavan K, Chieng LO, Wang MY, Hofstetter CP. Early experience with endoscopic revision of lumbar spinal fusions. Neurosurg Focus. 2016;40:1-5.

30. Telfeian A. Endoscopic foraminotomy for recurrent lumbar radiculopathy after TLIF: technical report. Surg Neurol Int. 2015;6:4-7. 